\title{
Comparative Performances of an Activated Sludge Process and a Membrane Bioreactor for the Treatment of a Textile Industry Effluent
} Chamam $\mathbf{B}^{1^{*}}$, Heran $\mathbf{M}^{2}$, Amar RB $^{3}$ and Grasmick $\mathrm{A}^{2}$

${ }^{1}$ Water Researches and Technolgies Centre, University in Montpellier, France

${ }^{2}$ University of Montpellier, France

${ }^{3}$ Faculty of Sciences of Sfax, University of Sfax, Tunisia

*Corresponding author: Chamam B, Water Researches and Technolgies Centre, University in Montpellier, France, Tel: +21695750206; E-mail: baha.chamam@certe.rnrt.tn

Received date: October 02, 2017; Accepted date: October 11, 2017; Published date: October 16, 2017

Copyright: ( 2017 Chamam B, et al. This is an open-access article distributed under the terms of the Creative Commons Attribution License, which permits unrestricted use, distribution, and reproduction in any medium, provided the original author and source are credited.

\begin{abstract}
The aim of our work is to compare the performances and the quality of treated water of a Tunisian textile industry through a conventional activated sludge (CAS) and a membrane bioreactor (MBR). During the first period, CAS and MBR1 worked under similar biological conditions (MLSS of 4-6 g. $\mathrm{L}^{-1}$ ). MBR showed a better global efficiency. Permeate of MBR was always free from TSS and turbidity whereas CAS treated water contained TSS and turbidity varying respectively between 0 and $0.13 \mathrm{~g} \cdot \mathrm{L}^{-1}$ and 10 and $20 \mathrm{NTU}$. If colour and soluble COD removal efficiency was closed (95\% and $97 \%)$, it appeared necessary to add coagulant in the CAS to insure an adequate sludge settling and complete the colour removal. During the second period, the sludge retention time was increased in the MBR2 in order to reach 8-10 g. $\mathrm{L}^{-1}$ of suspended solids. The COD effluent value was further reduced (MBR2: $50 \mathrm{mg} \cdot \mathrm{L}^{-1}$,

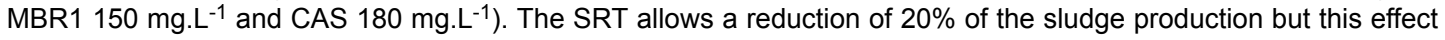
was counterbalance by rheological sludge properties. Furthermore, the MBR has shown great aptitude to withstand high loading rate variations and to product a constant quality effluent.
\end{abstract}

Keywords: Textile effluent; Membrane bioreactor; Conventional activated sludge; Wastewater treatment; Sludge production

\section{Introduction}

Textile industry is one of the key areas in North Africa, and especially in Tunisia which is among the major exporters of textile and clothing for the European market. End of 2011, Europe was still responsible for $96 \%$ of the exportations in this sector. Today, textile industry still counts more than 2000 production units, where $35 \%$ are located in Tunisia, employing over 200000 people. It also accounts $36 \%$ of Tunisian exports and $40 \%$ of jobs in the manufacturing industry [1].

However, Tunisia is a Mediterranean country located on south coasts which is characterized by semi-arid climate. Since the two last decades, the combination of climate and demographical evolutions results in a decrease of water availability both for drinking water supply and irrigation management. Moreover, the industrial development has brought an increasing demand for water and waste water treatment. And in the field of textile, dyeing industry consumes a great amount of water used as solvent. Reactive dyeing of $1 \mathrm{~kg}$ of cotton requires about 150 Litres of water and $40 \mathrm{~g}$ of reactive dye [2] resulting in a large volume of strongly coloured effluents. Moreover, the degree of dye fixation on a fibre varies depending on the type of fibre to be dyed and the dying parameters. For sulphur dyes, the percentage of non-fixed dye that may be discharged in the effluent is around 25 to $30 \%$ [3]. This is why their wastewaters carry numerous and different pollutants diluted in a large amount of water.

In fact, reactive dyes have poor fixation rates and hence may be hard to remove from wastewaters because of their low biodegradability and their low level of absorption into activated sludge suspended solids [4].
During the dyeing steps of textile materials, the generated effluent resulted from at least 9 baths: dyeing, finishing, coating, bleaching and washing baths [4]. Several Steps used salt and high temperature (up to $90^{\circ} \mathrm{C}$ ) resulting in a final high temperature effluent between 35 and $40^{\circ} \mathrm{C}$ and high salt content (salinity between 7 and 10 g. $\mathrm{L}^{-1}$ in this studied case effluent).

Thus, the large volumes of effluents often produced are heavily loaded with pollutants, turbidity and highly concentrated in salts. A significant improvement in effluent quality is required before discharged in the environment.

From an environmental point of view, Tunisia is considered one of the leader developing countries in the field of water treatment and reuse to minimise losses of water. Tunisian legislations and regulations impose high limit pollution values for discharge into a municipal wastewater treatment plants or into the environment: For example, regarding discharge into the environment, COD limit value is about $100 \mathrm{mg} . \mathrm{L}^{-1}$ against $1000 \mathrm{mg} . \mathrm{L}^{-1}$ concerning discharge into a municipal wastewater treatment plant. It can be seen that the norms applied to discharge into a municipal treatment plant are less strict than those applied to discharge into the environment. Besides, up to $65 \%$ of wastewater is recycled [5].

Since the last decay, textile sector knows a great expansion in Tunisia. The region of the Sahel in the east of the country has the greatest concentration of textile companies. The textile waste effluents correspond to the total volume collected from the different baths necessary in the dyeing industry like bleaching and finishing treatment and dyeing auxiliaries. The average daily water consumption for the SITEX Company located at Ksar Helal, which uses sulphur dyeing processes and cotton fibres, was estimated to be around $2500 \mathrm{~m}^{3} \cdot \mathrm{d}^{-1}$. 
Textile effluents are one of the wastewaters that are very difficult to treat satisfactorily to reach the discharge norms. Hessel et al. [3] have given an interesting review about legislation for dye house effluents in France and in other countries around the world where they examine the limit values of the most representative parameters in the textile industry.

Studies regarding the treatment processes were carried out by different investigators $[2,4,6,7]$. According to the literature, several processes are used to eliminate colour and organic load.

Generally, coagulation is a widely applied process as a pre-treatment prior to principal treatment (by activated sludge, oxidation or membrane) to remove colloidal particulates and dissolved organic substances. Such combinations of biological, physical and chemical processes are necessary to break down the dye molecules which are highly structured polymers. Sheng et al. [8] have find that the combination of ozonation, chemical coagulation and the sludge processes can provide a very effective mean to reduce colour and chemical oxygen demand (COD) of the textile waste effluents. Ozonation leads to the decomposing of the highly structured dye molecules into smaller ones which can be easily biodegraded in an activated sludge process.

Adsorption process was also investigated $[7,8]$ to remove various kinds of colours composing textile. Some adsorbents of specific characteristics basing on properties as ideal for organic matter adsorbent was used, like fly ash which is chose for its low cost compared to active carbon.

The efficiency of currently process was generally instable in relation to the important daily and seasonal variation of effluents volume, and organic and mineral load [9]. An adequate process that supports to meet occasional picks of effluent volume and organic load must be used.

Recently, membrane technology like ultrafiltration and Nano filtration have been used in the field of textile waste water treatment in order to remove COD (chemical oxygen demand) and colour, and in order to permit reuse of salts and water $[2,4,10,11]$.

Membranes could also be useful when it is combined with conventional chemical or biological treatment systems. Thus membrane bioreactor (MBR) process which is a combination of activated sludge and membrane separation has several advantages over the different processes currently used for the treatment of textile waste water. In this system, the secondary sedimentation tank was replaced by membrane units. A higher degree of wastewater treatment can then be obtained in term of BOD (biological oxygen demand) and COD removal due to higher biomass concentration in the reactor [12]. Treated water produced was generally free from suspended solids and microorganisms due to membrane cut off. Generally, to avoid fouling, the use of back pulsing allow to maintain a high constant permeate flux for a long period. The treated water produced is generally suitable for reuse in the dying process. A step of desalination by Nano filtration or reverse osmosis could be directly added to produce water of free salt which is necessary for some dying baths [4].

This paper describes an investigation of real textile wastewater treatment by MBR technology. The new water treatment performances generated were then compared to a conventional activated sludge process (industrial site) in terms of organic load removal efficiency and sludge properties.

\section{Materials and Methods}

\section{Experimental MBR plant}

Experiments were carried out on a MBR pilot unit built by POLYMEM (France) located in the waste water treatment plant of SITEX Company at Ksar Helal (Tunisia). The MBR unit (Figure 1) is equipped with an extern membrane module $(\mathrm{C})$ where the circulation is induced by air-lift. The biological reactor (B) was filled with activated sludge from SITEX conventional activated sludge plant. Then, the sludge (30 litres) is continuously feed with the real SITEX effluent (A). The both units (CAS and BRM) work at $1.36 \mathrm{~kg}$ COD. $m^{-3} \cdot d^{-1}$.

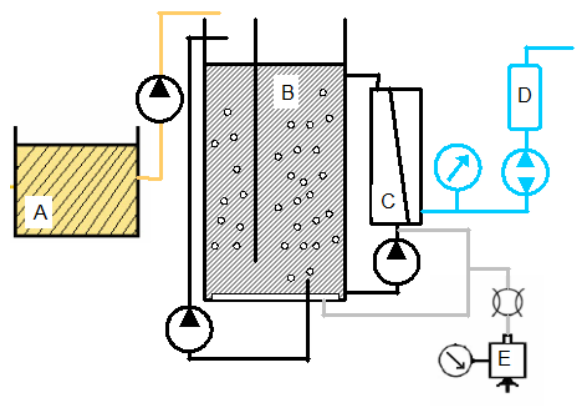

Figure 1: Schematic MBR pilot plant. A: Textile wastewater (feed) B: Biological reactor C: Membrane module D: Backwash bottle E: Air sparger.

Oxygenation and sludge agitation (E) are assured through air sparger. The dissolved oxygen concentration was kept higher than 2 mg. $\mathrm{L}^{-1}$ during all the experiment.

The external module is equipped with a set of hollow fibres membranes. Air injection (E) is imposed at the bottom of the membranes, ensuring a vertical air lift circulation which led to important shear stresses closed to the membrane surface. During the filtration, the permeat flux was maintained constant and equal to 13.5 L.d $\mathrm{d}^{-1}, \quad(\mathrm{Jw}=4.1$ LMH $)$ while pressure transducers allowed the monitoring of the Trans membrane pressure (TMP).

Two different working period have been performed; Period 1: BMR was operated at low mixed liquor suspended solid MLSS concentration (5 g.L $\mathrm{L}^{-1}$ ) and Period 2: BMR was operated at high MLSS (10 g.L $\left.{ }^{-1}\right)$. The influence of the separation performances was then investigated taking into account the biological parameters like the sludge retention time SRT. Nevertheless, some modifications were required in order to work under high sludge concentration:

-A pump was placed between the biological reactor and the membrane module in order to ensure the sludge flow between the reactor and the filtration unit (The airlift circulation loop is indeed less efficient at 10 gTSS.L $\left.{ }^{-1}\right)$.

-A backwash (D) was also added in order to minimize membrane fouling (Sludge deposit on the membrane surface) (Figure 1).

During a backwash step, the permeate pump turns in the opposite direction and washes the membrane with the bottle of permeate (D). A backwash is so carried out every hour during 15 seconds where about $100 \mathrm{ml}$ of permeate was used. To compensate this momentary 
permeate loss and to maintain the same daily average flow, permeation flow is increased during the filtration to reach a specific permeate flux Jw equal to $4.6 \mathrm{LMH}$. The backwashing program is controlled by an automation devise.

\section{Characterization of textile effluent}

The influents come from a dyed Djean (cotton) factory located in Tunisia, which produces on average $2200 \mathrm{~m}^{3} \cdot \mathrm{d}^{-1}$ of wastewater. In order to discharge the effluent in the municipal sewer system, the following value must be reached (TSS $<400 \mathrm{mg} . \mathrm{L}^{-1}, 6.5<\mathrm{pH}<9$, COD $<1000$ mg.L ${ }^{-1}$, BOD5 $<400$ mg. $L^{-1}$.

To take into account the daily fluctuation of the influent composition samples was taken every hour. If the temperature and the $\mathrm{pH}$ remain almost invariant: $25-35^{\circ} \mathrm{C}$ and 12 respectively, the total COD (COD total), soluble COD (COD soluble), as well as colour, MLSS (suspended substances) and MVLSS volatile substances) undergo a very important variation (Table 1).

\begin{tabular}{|l|l|l|}
\hline Parameters & Unit & value \\
\hline CODtotal & mg. $\mathrm{L}^{-1}$ & $1500-4000$ \\
CODsoluble $(0.2 \mu \mathrm{m})$ & $\mathrm{mg} \cdot \mathrm{L}^{-1}$ & $500-2000$ \\
MLSS & g. L-1 & $0.35-0.73$ \\
MVLSS & g. L-1 & $0.03-0.65$ \\
Colourtotal & U.C & $1300-6000$ \\
Coloursoluble & U.C & $600-2200$ \\
\hline
\end{tabular}

Table 1: Characteristics of SITEX influent (taking into account the daily variation).

\section{Conventional activated sludge process}

In order to homogenize the effluent, a homogenization tank was used and a screening step stops the larger particles. Then the $\mathrm{pH}$ is lowered by adding mainly sulphuric acid, or phosphoric acid, or in rarer cases $\mathrm{CO}_{2}$ in a neutralization tank. The biological process takes place in two channels of oxidation of a capacity of $2500 \mathrm{~m}^{3}$ each. Brush rotor technology provides oxygen with an oxygenation capacity of $6912 \mathrm{~kg} \mathrm{O}_{2} \cdot \mathrm{d}^{-1}$. The hydraulic retention time is more or less 5 days.

Treated water was then separated from the biomass due to a contribution of coagulant (EPENWAT) of $40 \mathrm{gm}^{-3}$ used for optimize the liquid solid separation step and finishing the colour removal. The separation takes place in two clarifiers (Total volume of $560 \mathrm{~m}^{3}$ ). A part of settled sludge will be recycled in the biologic basin. While, the rest, (mass of excess sludge), is steering towards the "sludge" line composed of thickener and belt filter. Sludge production varies from 1300 to $2000 \mathrm{~kg} \cdot \mathrm{d}^{-1}$.

\section{Results and Discussion}

\section{Low MLSS operation mode (period 1)}

COD removal: The evolution of the soluble COD shows that a period of sludge acclimatization (20 days) was necessary to stabilize the biological behaviour (Figure 2). This result was noticed already by other authors [12]. During this period, the soluble COD was very high with regard to the permeate value which is closed to the value of CAS SITEX treated water. The membrane in MBR system seems enhanced the water quality in term of pollutant retention. In fact, the MBR system presents value slightly inferior $\left(150 \mathrm{mg} . \mathrm{L}^{-1}\right)$ to the whole SITEX treatment plant (180 mg.L $\left.\mathrm{L}^{-1}\right)$.

Colour removal: Colour intensity of the treated water from the MBR is slightly lower than that obtained from conventional SITEX plant (between 100 and 200 U.C) (Figure 3). This result indicates that ultrafiltration membrane is unfortunately not sufficient to retain colour. Nevertheless, the MBR effluent never exceeds the value of 200 U.C whereas CAS effluent reach values between 200 and 300 U.C during the 15-th and the 25-th day.

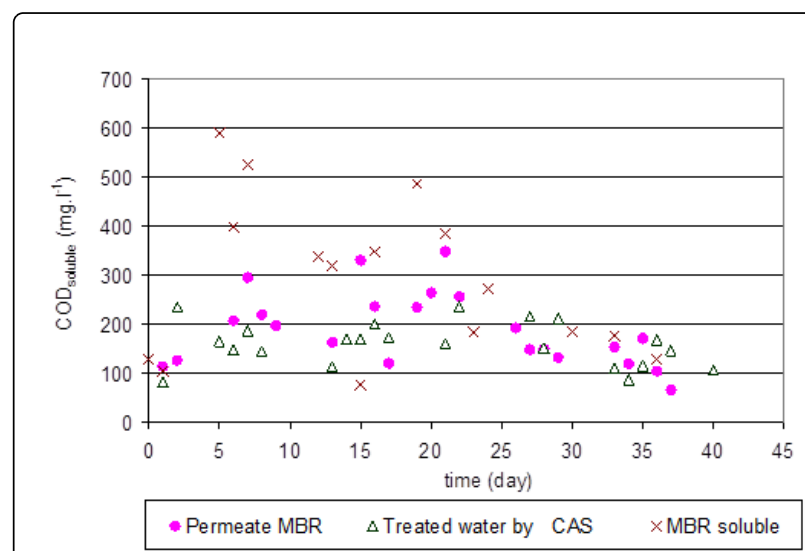

Figure 2: Variation of COD soluble in permeate, MBR and CAS treated water during 'period 1 '.

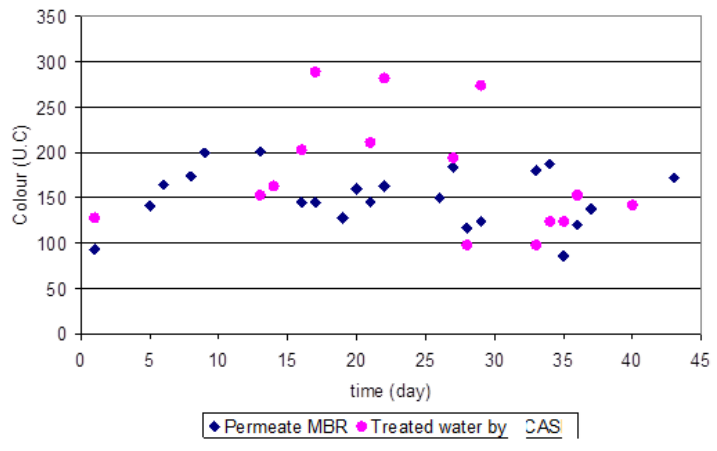

Figure 3: Variation with time of colour intensity in the treated water from MBR and CAS during 'period 1'.

Total Suspended Solid (TSS) and turbidity removal: The TSS in the SITEX treated water varied between 0 and 0.13 g.L.-1, whereas the MBR allows free TSS treated water thanks to membrane which constitute a barrier for suspended matter and microorganisms.

The CAS treated water turbidity varying between 10 and 20 NTU, whereas these values are constant and lower than 2 NTU for the permeate provided by the MBR system. These results are in accordance with the TSS removal by the Ultrafiltration membrane.

It is important to notice that for the CAS, the final treatment performances are attributed to the combined effect of sedimentation and coagulation which happened in the secondary sedimentation tank and lead to an increase of the liquid/solid separation efficiency. 
Citation: Chamam B, Heran M, Amar RB, Grasmick A (2017) Comparative Performances of an Activated Sludge Process and a Membrane Bioreactor for the Treatment of a Textile Industry Effluent. J Bioprocess Biotech 7: 310. doi:10.4172/2155-9821.1000310

Page 4 of 6

The major disadvantage of this system remains the addition of coagulant reagent which contributes also to increase the treatment cost and lead to a production of additional sludge.

Sludge production: Under MBR conditions, the average production of sludge in term of COD and MLSS is estimated respectively to 260 $\mathrm{mg} \cdot \mathrm{L}^{-1} \cdot \mathrm{d}^{-1}$ and $150 \mathrm{mg} \cdot \mathrm{L}^{-1} \cdot \mathrm{d}^{-1}$. The conversion rates are low both in term of $\mathrm{COD}\left(\mathrm{Y}=0.19 \mathrm{~g}\right.$ CODproduced. $\mathrm{g}^{-1} \mathrm{COD}$ eliminated) and in term of MLSS $\left(\mathrm{Y}^{*}=0.11\right.$ gMLSS produced. $\mathrm{g}^{-1} \mathrm{COD}$ eliminated) (Figure 4). The ratio ' $\mathrm{Y} / \mathrm{Y}^{*}$ ' versus time is almost constant and equal to 1.8 (Table 2). This mean value is lower than those obtained from CAS $\left(\mathrm{Y}=0.25 \mathrm{~g}\right.$ COD produced. $\mathrm{g}^{-1}$ COD eliminated; $\mathrm{Y}^{*}=0.13$ gMLSS produced. $\mathrm{g}^{-1} \mathrm{COD}$ eliminated; $\left.\mathrm{Y} / \mathrm{Y}^{*}=0.19\right)$ because of the higher sludge retention time in the MBR and the non-addition of reagent compound.

\begin{tabular}{|l|l|l|l|l|}
\hline & \\
& & & & \\
\end{tabular}

Table 2: Sludge production and conversion rates in MBR 'period 1'.

\section{High MLSS operating mode (period 2)}

COD removal: During the experiment at high MLSS concentration (almost 10 g. $\mathrm{L}^{-1}$ ), the MBR COD effluent is inferior to $100 \mathrm{mg} . \mathrm{L}^{-1}$. (Average value $=50 \mathrm{mg} \cdot \mathrm{L}^{-1}$ ) Whereas in CAS conditions, the treated water COD was always higher than $150 \mathrm{mg} \cdot \mathrm{L}^{-1}$ and reaches sometimes $300 \mathrm{mg}^{-1}$ (Figure 5).

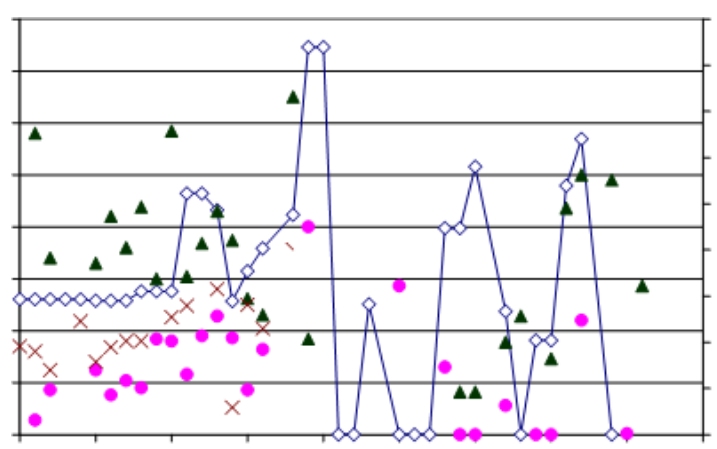

Figure 5: Variation of $\mathrm{COD}_{\text {solube }}$ and $\mathrm{COD}_{\text {permeate }}$ with time during 'period 2'.

There is only a weak difference between soluble COD concentration in reactor and in permeate. This point underlines that high suspended solids (i.e., high sludge retention time) can adsorb and oxide more easily the compounds used in dye industry. These better performances are associated to the increase of the sludge retention time in MBR which allows a better cultures adaptation to the influent minimizing the soluble reactor concentration.

MBR efficiency appears more stable and better than the CAS. COD elimination is always upper than $97 \%$ against $93 \%$ on average CAS conditions (Figure 6).

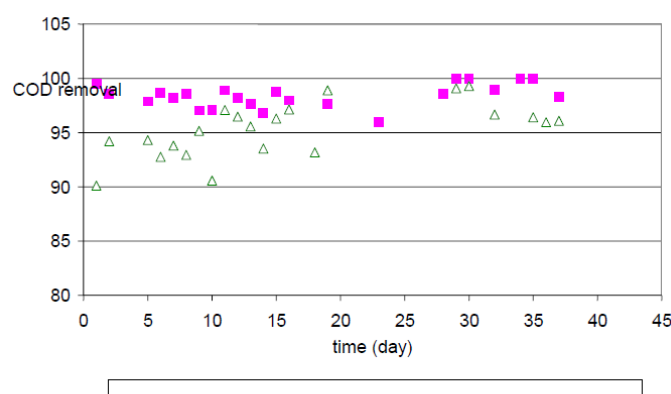

- COD removal by MBR $\triangle \mathrm{COD}$ removal by CAS

Figure 6: Variation of COD removal with time in MBR and CAS conditions during 'period 2'. 
Citation: Chamam B, Heran M, Amar RB, Grasmick A (2017) Comparative Performances of an Activated Sludge Process and a Membrane Bioreactor for the Treatment of a Textile Industry Effluent. J Bioprocess Biotech 7: 310. doi:10.4172/2155-9821.1000310

Page 5 of 6

Colour removal: MBR performances in term of colour removal are better than CAS conditions (150 UC against 300 UC on average) (Figure 7). Nevertheless, compared with results on period 1, we notice that colour removal efficiency is appreciably the same independent of the load. The MLSS increase from 5 g.L $\mathrm{L}^{-1}$ to $10 \mathrm{~g} . \mathrm{L}^{-1}$ had unfortunately no effect on the colour removal. The point may confirm the nonbiodegradability of the used dyes. However, the stability of the MBR treated water must be highlighted.

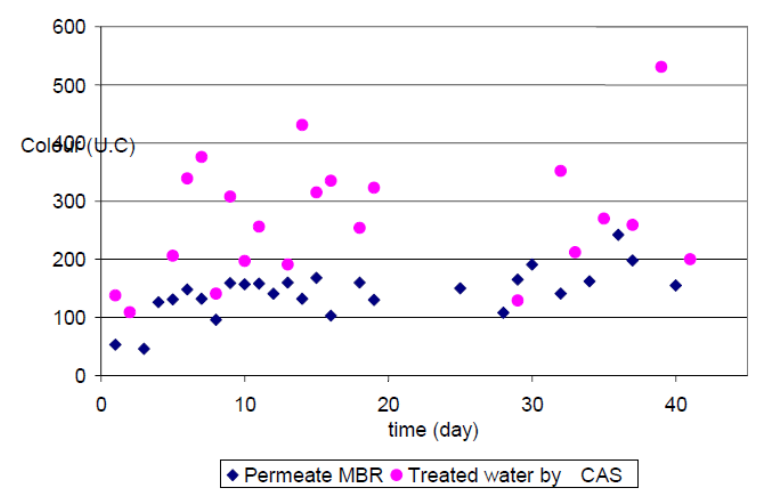

Figure 7: Variation of colour intensity with time in the treated water from MBR and CAS during 'period 2'.

Turbidity and TSS removal: As it was observed during the period 1, the treatment by MBR leads to an almost-total TSS elimination, in spite of the high MLSS concentration in the biological reactor. Thus, MBR effluent is always free of turbidity $(<2$ NTU) because of the elimination of TSS by membrane. Once again; the advantage of MBR treatment is confirmed. Indeed, if the conventional activated sludge plant is sensitive to load increase or pick load, the MBR presents a better high capacity to withstand high loading rate variations notably because of the total biomass retention by the membrane barrier whatever the biomass flocculation state.

\section{Sludge production and conversion rate}

Figure 8 shows a progressive evolution of MLSS taking into account the extraction of sludge. MLSS production is equal to $124 \mathrm{mg} \cdot \mathrm{L}^{-1} \cdot \mathrm{d}^{-1}$. This value is slightly lower than those obtained in period 1 (150 $\left.\mathrm{mg} \cdot \mathrm{L}^{-1} \cdot \mathrm{d}^{-1}\right)$. This reduction is due to the enhancement of the influent biodegradability may be due to the reduction of the F/M ratio (Food/ Micro-organisms).

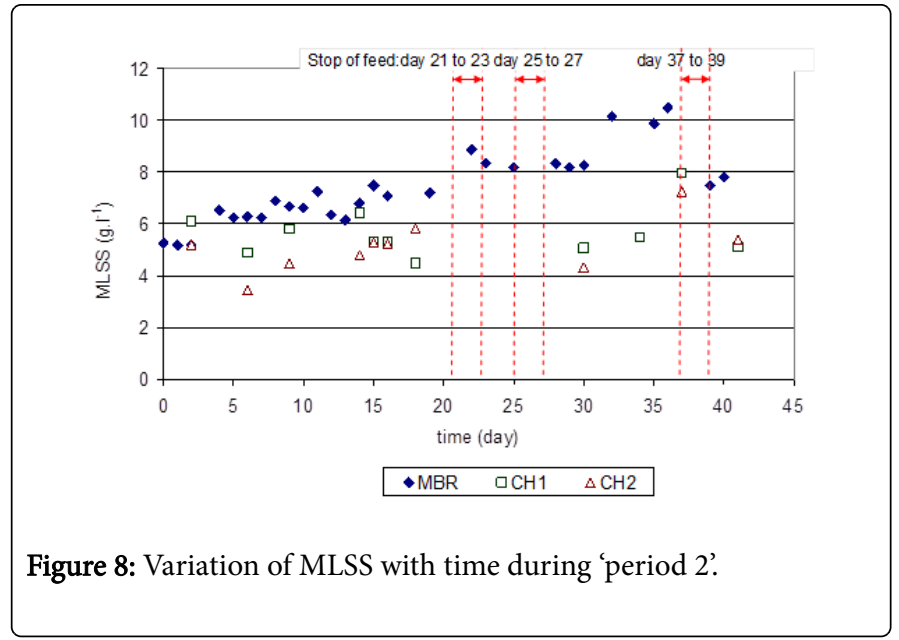

The conversion rate $\mathrm{Y}^{*}$ (MLSS) is then equal to $0.085 \mathrm{~g}$ MLSS produced. $\mathrm{g}^{-1} \mathrm{COD}$ eliminated. The decrease of the $\mathrm{F} / \mathrm{M}$ ratio (for the same BOD loading) allows a decrease of $20 \%$ of the conversion rate.

\section{Oxygen consumption}

Respiration in MBR and in the oxidation channels is relatively constant, this value varies between 10 and $20 \mathrm{mg} \cdot \mathrm{L}^{-1} \cdot \mathrm{h}^{-1}$. The oxygen demand is equal to $0.25 \mathrm{~g} \mathrm{O}_{2} \cdot \mathrm{g}^{-1} \mathrm{COD}$ removed (Figure 9). The oxygen consumption is more a function of the BOD loading than a function of the MLSS concentration. This point counterbalances on one side the benefit effect of MLSS concentration on the reduction of sludge production and on the other side the constant OUR whatever the MLSS concentration. In fact, working with high sludge ages or high MLSS offers no significant saving in terms of active biomass (OUR=Constant) in the reactor for a defined volumetric loading rate. On the contrary, this may be unfavourable in terms of total suspended solids concentration thus generating rheological sludge properties that penalize the phenomena of mixing, oxygenation and membrane separation.

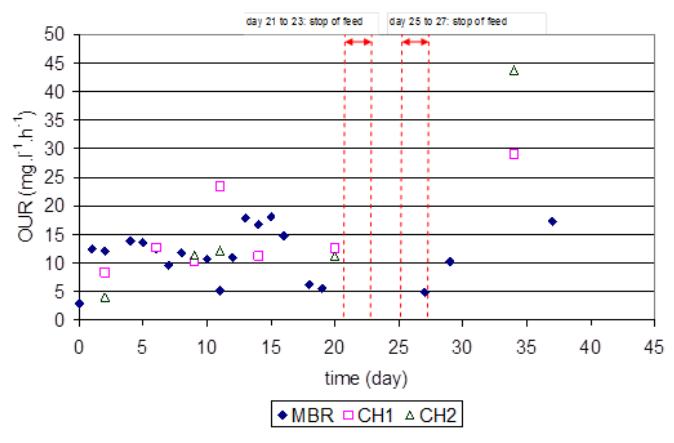

Figure 9: Oxygen consumption in MBR and CAS during 'period 2'.

\section{Membrane fouling control}

If the selectivity of the membrane was clearly favourable to a high quality of the treated water, the permeability remained weak during runs because of a significant fouling onto the membrane surface. The control of fouling was effective because of working under low specific 
Citation: Chamam B, Heran M, Amar RB, Grasmick A (2017) Comparative Performances of an Activated Sludge Process and a Membrane Bioreactor for the Treatment of a Textile Industry Effluent. J Bioprocess Biotech 7: 310. doi:10.4172/2155-9821.1000310

Page 6 of 6

permeate flux $(\mathrm{J}<5 \mathrm{LMH})$. In fact, the initial choice of the membrane module configuration (high packing density, $300 \mathrm{~m}^{2}$ membrane. $\mathrm{m}^{-3}$ installed, low fibre diameter, $1 \mathrm{~mm}$, and non-homogeneous membrane air injection) was not the best configuration to maintain sustainable filtration condition under higher permeate flux. Several Backwash strategies were used in order to minimize fouling. Nevertheless, even a backwash per day for period 1 or a backwash per hour (period 2) did not succeed to allow higher permeate flux without favouring module clogging. A constant TMP increase of 0.03 bar.d $^{-1}$ was observed. A chemical cleaning was performed each 25 days. Numerous studies must be done in order to optimize the filtration units.

\section{Conclusion}

The MBR treatment of textile influents was studied under different F/M ratio (MLSS concentrations) and compared to conventional activated sludge plant (CAS). Under similar biological conditions, the MBR system showed a better global efficiency than the CAS even with chemical addition (coagulant) in the secondary sedimentation tank. Then, the results confirmed the high capacity of MBR to withstand high loading rate variations and to product a constant quality effluent without solids in suspension and with low turbidity what allows downstream treatment such as desalination if necessary. The biomass activity in MBR appeared clearly dependent of the organic volumetric load and then the increase of SRT can only be interesting in term of decrease of installation footprint. The membrane module configuration appeared as essential to control membrane fouling.

\section{References}

1. Tunisian Textile: When social, political and economic responsabilities compete (2012) CAP counsil.
2. Allègre C, Moulin P, Maisseu M, Charbit F (2006) Treatment and reuse of reactive dyeing effluents. Journal of Membrane Sciences 269: 15-20.

3. Hessel C, Allègre C, Maisseu M, Charbit F (2007) Guidelines and legislation for dye house effluents. Journal of Environmental Management 83: $171-180$.

4. Maisseu M, Allègre C, Charbit F, Moulin P (2006) Treatment and recovery of effluents from cotton dyeing by depletion with reactive dyes. Recent Advances in Process Engineering 93: 1-8.

5. Ennabli M (2005) The problems of water in the countries of the south of my Mediterranean Sea. 2nd Feranco-Maghrebine Summer School, Membrane Science and Technology, STM2, Monastir, Tunisia.

6. Basava Rao VV, Ram Mohan Rao S (2006) Adsorption studies on treatment of textile dyeing industrial effluent by flyash. Chemical Engineering Journal 16: 77-84.

7. Donna T, Rakesh T, Awdhesh K, Chandralata R (2006) Enhanced production of laccase by a marine fungus during treatment of colored effluents and synthetic dyes. Enzyme and Microbial Technology 38: 504-511.

8. Ababou N, Meziane D, Kherbeche A, Chaqroune A (2002) Study of the adsorption of textile dyes on a Moroccan diatomine. Phys Chem. News 6: 130-134.

9. Sheng H, Chi M (1993) Treatment of textile effluents by ozonation and chemical coagulation. Water Research 12: 1743-1748.

10. Suksaroj C, Héran M, Allègre C, Persin F (2005) Treatment of textile plant effluent by nanofiltration and/or reverse osmosis for water reuse. Desalination 178: 333-341.

11. Suksaroj C, Héran M, Orantes J, Wisniewski C (2006) The influence of operating conditions on permeability changes in a submerged membrane bioreactor. Separation and Purification Technology 52: 60-66.

12. Barrios A, Barbot E, Marrot B (2006) Degradation of synthetic phenolcontaining wastewaters by MBR. Journal of Membrane Sciences 28: 288-296. 